\title{
SINALIZAÇÕES PRESENTES NA OBRA ESTOCAGEM \#6, CONSIDERAÇÕES SOBRE O QUE ESTÁ POR VIR EM UMA PESQUISA EM ARTES VISUAIS
}

\author{
Anderson dos Santos Batista (acadêmico - PPGAV-UFRGS) ${ }^{1}$ \\ feruchomarquesu@gmail.com \\ Maria Ivone dos Santos (orientadora - PPGAV-UFRGS) \\ maria.ivone@ufrgs.br
}

\begin{abstract}
RESUMO
Este artigo reflete sobre o percurso atual da pesquisa de mestrado em artes visuais, utilizando como gatilho para se considerar o conceito de sinalização a obra Estocagem \#6. Dividido em duas partes, este artigo na primeira aponta para conceitos e procedimentos operatórios já presentes anteriormente na pesquisa como os processos silenciosos, as estocagens e os soterramentos, que se dialogam, se misturam ou se justapõem. Na segunda parte, após mapeamento dos conceitos presentes na pesquisa e especificamente na obra, parte-se para novas propostas, em especial, desdobramentos a partir do termo sinalização.
\end{abstract}

Palavra-chave: Sinalização; Estocagem; Soterramentos; Processos silenciosos; Pesquisa em arte

\section{INTRODUÇÃO}

O texto que segue sinaliza para pontos presentes na obra Estocagem $\# 6^{2}, 2016$, bem como traz novas considerações sobre a obra, dialogando com a andamento atual da pesquisa de mestrado em Artes Visuais feita na UFRGS. Apresenta seus desdobramentos, no que tange à inserção do conceito de sinalização em nova leitura do objeto artístico, bem como, conceito com potencial para novas ações na pesquisa, através de aproximações, tensionamentos, relações com artistas e pensadores da arte, ampliando criticamente uma discussão sobre a obra em questão.

\footnotetext{
${ }^{1}$ Apresento-me no âmbito de produção em arte como Fercho Marquéz.

${ }^{2}$ Obra produzida em 2016, durante o Trabalho de Conclusão de Curso em Artes Visuais, na UEL, intitulado Ruptilidade da Vida, Ductilidade da Morte, orientado pela profa. Maria Carla Guarinello de Araujo Moreira entre 2015 e 2016. Medindo $30 \mathrm{~cm}$ x $15 \mathrm{~cm}$ x $15 \mathrm{~cm}$, Estocagem \#6 é feita de uma caixa de madeira com 9 vãos de $5 \mathrm{~cm}$ x $5 \mathrm{~cm}$ que estocam, pendurada à parede, 9 blocos de glicerina vermelha, medindo aproximadamente $5 \mathrm{~cm}$ x $5 \mathrm{~cm} \mathrm{x} 10 \mathrm{~cm}$.
} 
Abordo então o primeiro conjunto de sinalizações, chamado sinalizações de processos silenciosos, no qual trato sobre o conceito de processos silenciosos e como ele se encontra presente em procedimentos operatórios como nas estocagens e nos soterramentos. Trago à tona, os aspectos materiais a que os processos silenciosos se referem, como as movimentações físico-químicas pelas quais a glicerina passa, como fundição, solidificação, derretimentos, impregnação e transpiração. Está presente, pois, um conjunto de rastros e impressões que pela sua fragilidade, a glicerina leva em si, não só pelas mudanças materiais propostas pelas mudanças de tempo, espaço, temperatura, como especialmente pelo seu contato com os moldes de madeira, com as madeiras que a estocam, com as mãos.

No segundo conjunto de sinalizações, sinalizo para a disposição dessa relação complexa glicerina-madeira nos espaços expositivos, procedimento operatório nomeado como estocagem. As sinalizações de estocagem discorrerem sobre como a estocagem se insere como dispositivo de apresentação da obra rúptil, discutindo sobre uma estocagem que no processo artístico se caracteriza como falha. Também introduzo a protoestocagem, instância anterior à da estocagem, onde me embrenharei pelo processo que localiza nas etapas de manipulação da glicerina em torno de seu corte, fundição, pigmentação, moldagem, secagem, retirada do molde e seu descanso, ou seja, os conteúdos que recebem o continente, neste caso, o duro que contém o mole. Aponto, então para seu caráter de novidade a se debruçar no decorrer da pesquisa.

O terceiro conjunto de sinalizações nomeado como soterramentos aborda as sinalizações de soterramento, ou seja, apresento a inserção dos soterramentos no andamento da pesquisa. Traz-se como sinalizações de soterramentos o caráter de horizontalidade presente nos blocos de glicerina estocados na obra em questão, os conceitos de entropia e soterramento que se inserem como propositores de novas relações pra se pensar a pesquisa em artes.

$\mathrm{Na}$ última parte, apresentam-se as sinalizações do que estão por vir, ou seja, as considerações para se pensar a continuação e o futuro da pesquisa. Presentes nestas considerações, estão o sentimento de superação das divisões dos conjuntos de sinalizações apresentadas anteriormente, bem como o pensamento de novos trabalhos que lidem com o conceito de sinalização, em seu sentido literal, presentes nas placas de trânsito ou faixas de rodovias e estradas. Relaciono, finalmente ao que se já tem da 
pesquisa, como a forma de disposição dos objetos no chão ou parede, a percepção conceitual, estrutural ou formal como tais como relacionada a uma apresentação de obra sinalizadora.

\section{SINALIZAÇÕES DE PROCESSOS SILENCIOSOS}

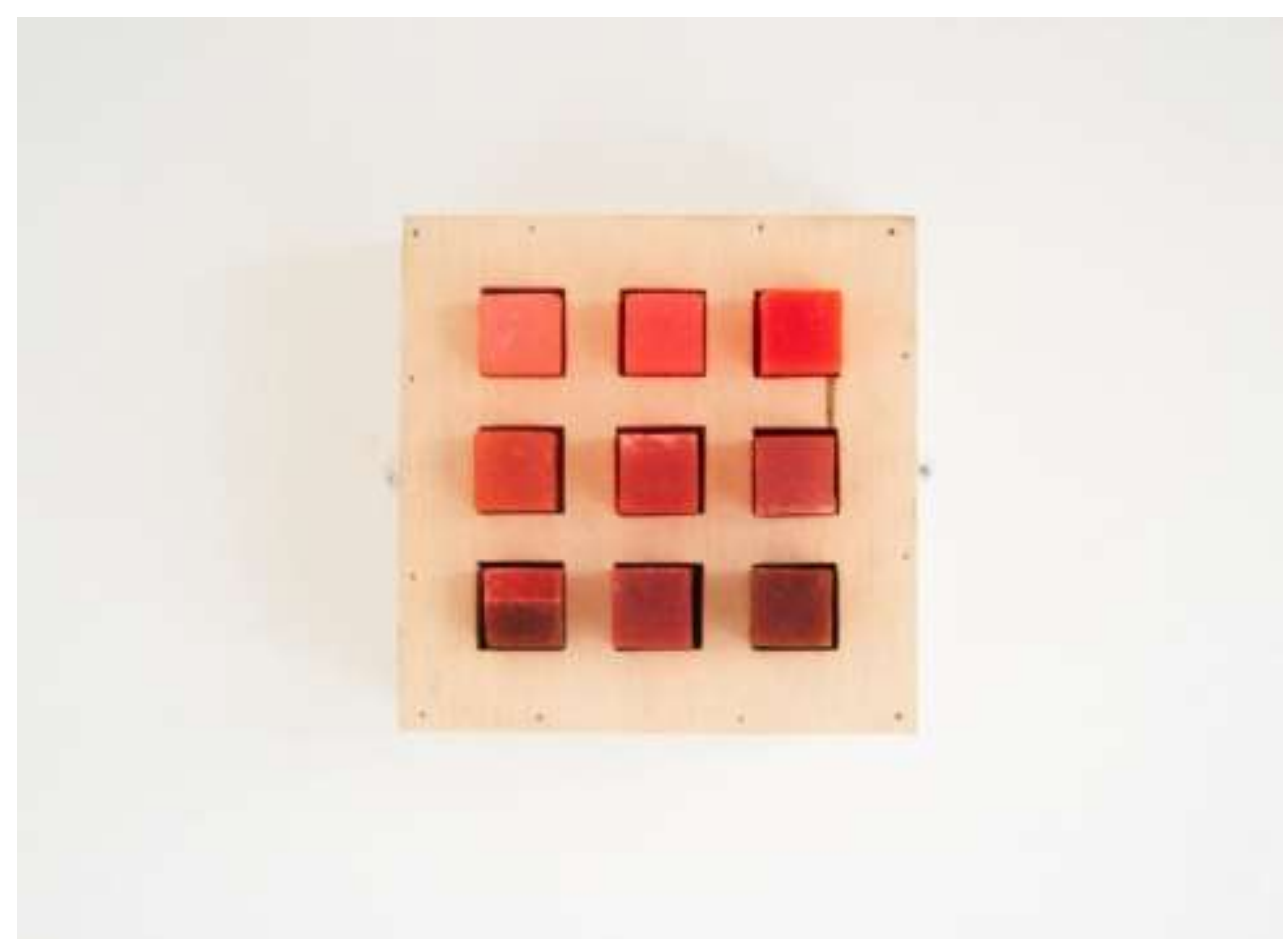

Figura 1. Fercho Marquéz (1992). Estocagem \#6. Madeira e glicerina, $30 \mathrm{~cm}$ x $30 \mathrm{~cm}$ x $15 \mathrm{~cm}$. Fonte: Acervo pessoal.

Estocagem \#6 (fig. 1) se constitui de uma caixa perfurada de madeira, onde em suas 9 perfurações, 9 blocos de glicerina vermelhos são dispostos nas mesmas. O objeto comumente se encontra pendurado na parede à altura média das pessoas para que essas possam se aproximarem e manusearem os blocos, conferindo com o tato a materialidade dos objetos. O tato vem como essa expansão da percepção do objeto.

A obra aponta, pois como um objeto a ser perfurado. Um objeto que é necessário perpassá-lo, pois há algo nele que está além do que a pressa permite ver. É necessário um contato mais agudo com a obra. E esse contato se dá através do espaço entre dois campos: um, o objeto fixado à parede, com glicerina disposta e o outro, o corpo do espectador. Esse 'espaço entre' é a glicerina que como um projetil é lançada para fora da escultura 
através da força que a mão confere a si. Como também, esse mesmo corpo que através da mão, introjeta nos vãos da madeira o outro corpo para seu descanso.

Esse jogo de capturar e perceber o bloco e repor no espaço inicial torna o espectador um manipulador, um manuseador. A obra propõe um manuseador que faz a obra estar em movimento, literalmente, num eterno vir e devir de cargas de material rúptil. A glicerina situada em uma escala que vai do material mais mole, frágil ou rúptil para o material mais duro, resistente, dúctil, se encontra no ponto no qual suas características se relacionariam com o âmbito da fragilidade e mais que isso, da não permanência de si, já que por ser frágil, está ao sabor dos tempos e ambientes. Esse caráter, como dito, instável se choca com a aparência estável que os objetos feitos de si, erroneamente nos faz pensar. Há todo um embate de permanência perante seu exterior que a visão não dá conta de mensurar. É necessário sentir a matéria com a própria matéria que nos constitui.

Esse dado de um material que se apresenta frágil, que não é constante perante o andamento de sua existência, mas que também não é percebido em um contato fugidiamente, neste caso a glicerina, é o condutor para se pensar uma aproximação e apreensão desse material. E é através do que chamo de processos silenciosos que a compreensão da matéria se dará e se instará como procedimento operatório na pesquisa.

À pesquisa, compreendo os processos silenciosos como sendo

[...] todos ou quaisquer processos pelos quais a matéria passa em seu cotidiano dentro da investigação, ou seja, são os dares a saber sobre as maneiras de agir e de interagir do material em relação às provações a que será submetido. Os processos silenciosos são tempos que se instauram, que, a saber, mostram sua mobilidade perante os espaços. (BATISTA, 2016.)

E essas movimentações da matéria, especificamente por sua condição rúptil, que promovem mudanças de caráter físico demonstram seus diálogos tensionados com o espaço externo: em um lugar quente, poderá iniciar o processo de derretimento, ficando viscosa, se o clima ficar úmido, essa poderá transpirar, se o tempo ficar seco, ela também secará, diminuindo de tamanho, por exemplo. Essa inconstância dinamita conclusões seguras em relação ao material, dando espaço para o devaneio da matéria. Se propor que a estoque, guarde, estas ações podem falhar, se pensá-la como ação definitiva, também pode não chegar a ocorrer. "Em suma, matérias sem dúvida reais, mas inconsistentes e móveis, reclamavam ser imaginadas em profundidade, numa intimidade de substância de força.” (BACHELARD, 2001, p. 2) 
E as sinalizações de processos silenciosos acontecendo, como já dito podem não serem percebidos se não houver uma pausa, um estacionamento perante a obra. Esses processos vão deixando rastros que com uma atenção pausada do espectador ou a disposição de entrar em contato com, tornando-se de espectador a manuseador, poderá depreender a existência de vãos entre os blocos dispostos dentro da glicerina e a área aberta na madeira para sua disposição, ou sentirá a glicerina atando-se a sua pele, abandonando sua disposição na madeira para sempre e lambuzando a sua ao mesmo tempo, que os óleos presentes na mão, vai como intempéries, modificando o que foi vertido em molde e disposto na madeira.

A glicerina então dialoga com o espaço, deixa seu rastro, impregna-se nos poros da madeira, lambuza e fertiliza esse osso de árvore. Vai demarcando sua presença ocupada, vai desbastando as marcas passadas dos processos de manipulação do artista, do transporte, de sua extração do molde, e vai agregando em si novas marcas, essas de caráter vivo, em uma série de sobreposições, anulações, acréscimos de informações. Sinalizações de que os processos de contato sucedem, que são imperceptíveis a primeira vista, mas quando uma nova realidade se abre, principalmente proporcionada através da atenção ao tato, o manuseador é inserido nessa realidade que o torna também aberto a se deixar tornar pegajoso ou rúptil também.

\section{SINALIZAÇÕES DE ESTOCAGEM}

Estocagem \#6 é a que melhor se apresenta como propositora de uma estocagem: como uma caixa vazada como prateleira, apresenta em modo de insinuação à manipulação, o descanso da glicerina após sua moldagem e extração do molde. A glicerina, constituída em formato de bloco, está apresentada de maneira não a partir de um ponto de visão de cima, mas de um ponto de vista frontal, podendo percebê-la pela sua largura e altura e não necessariamente pela sua profundidade, apesar de a apontar para um fundo da caixa, já que se projeta para fora.

Porém, o que se pensa de uma estocagem como função de guardar, armazenar para futuro uso, consumo ou consulta do material estocado é erodido pela não preservação do material estocado, já que, penso a estocagem como procedimento de operação falho em si mesmo. Em sua apresentação como estoque de algo inestocável é que as sinalizações de estocagem se apresentam. 
Essa estratégia de estocar, de armazenar os blocos de matéria-doce dentro das estruturas de madeira, sinaliza para suas próprias limitações, suas inconsistências, situando o próprio termo em torno de falibilidades e incapacidades das funções dos materiais designados dos processos. (BATISTA, 2016, p. 11)

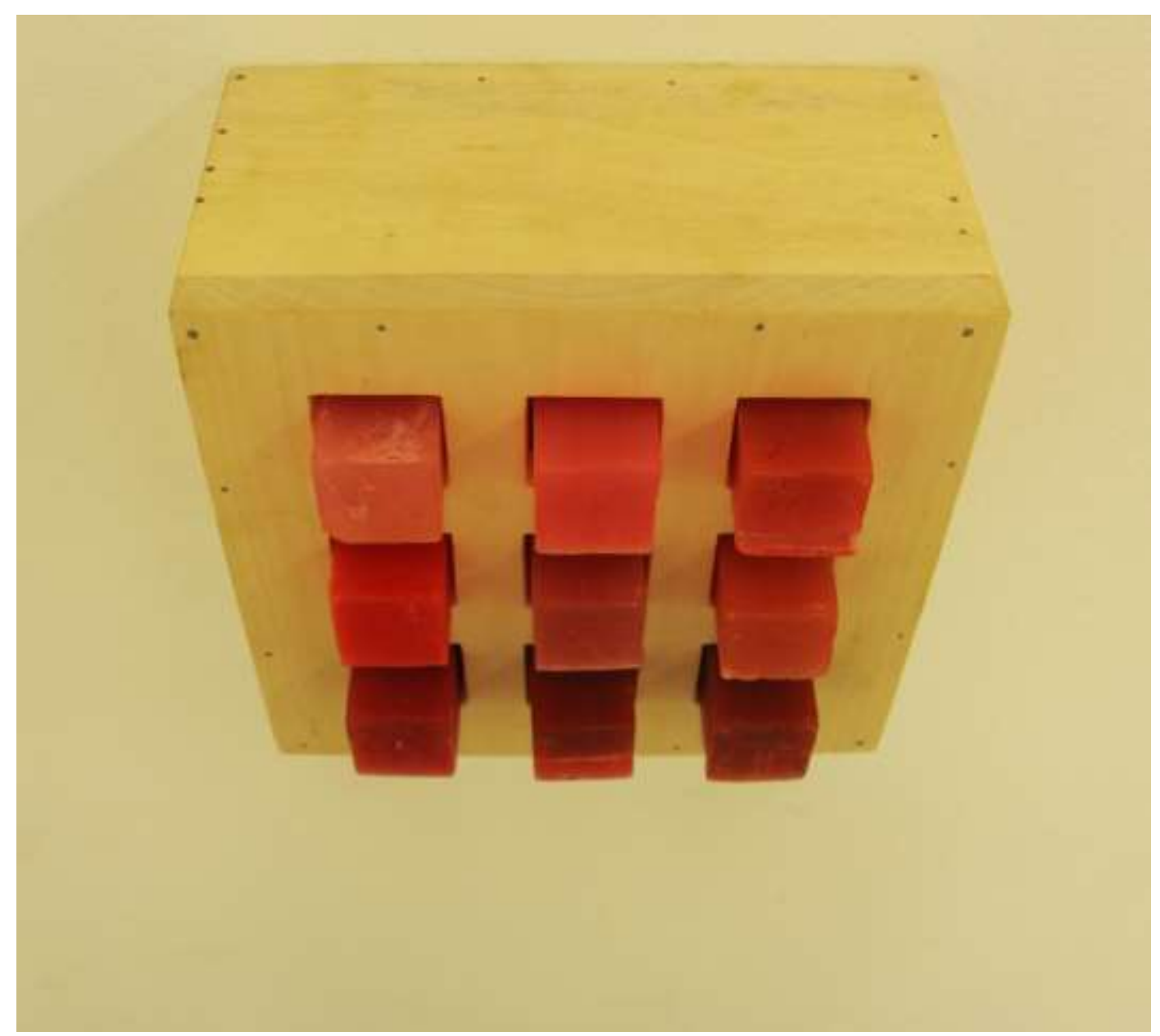

Figura 2: Fercho Marquéz. Estocagem \#6. Madeira e glicerina, $30 \mathrm{~cm}$ x $30 \mathrm{~cm}$ x $15 \mathrm{~cm}$. Fonte: acervo pessoal.

Pensando esta estocagem que falha, me remeto aos processos de manipulação da glicerina especificamente no momento de sua fundição, nos momentos pré-estocagens ou melhor dizendo, na instância de sua protoestocagem.

É nesses momentos em que a glicerina fundida se encontra em seu nível mais selvagem, diria assim, no qual por sua materialidade viscosa, apresentasse sua verdadeira face: a de um material que se camufla em uma solidez enganadora! Basta um pouco de calor para que excitada, mostre sua verdadeira face, ou melhor, sua verdadeira existência. Como um 
animal que precisa entrar na colcha para sobreviver, ou mudar de forma na metamorfose para se manter no mundo, a glicerina de certa forma também assim é.

Como uma memória física da matéria, da qual não se esquece de seus estados originários. É pedido uma volta ao estado de origem: líquido, viscoso. Talvez por isso, o conceito de estocagem falha: a glicerina se reporta para o seu passado, para seu estado embrionário, nascente, sem forma.

Na protoestocagem é que se percebe o que a matéria é. Sua forma oleosa que por momentos mutáveis vai sendo deposta, jorrada ou vertida nas formas. Talvez seja uma forma de sobrevivê-la, de ocupar pela permanência, nem que efêmera o mundo. E sua arquitetura orgânica desliza pelas superfícies contenedoras dos moldes, se espraiando, se dispondo uma sobre a outra. Morna, recém-saída do nascimento que o fogo acalentou, estaciona, sinalizando descanso. Chega-se o momento da sua petrificação incompleta. Porém, antes, como uma última ação antes de se congelar até o próximo estímulo, se embrenha nos poros da madeira que constituem os moldes e ali se fixa. Seriam necessários anos para que numa contração corpórea, o bloco se soltasse sozinho de seu abrigo madeireiro.

O artista, por vezes, tem responsabilidades que nunca são fáceis. É necessário, após a solidificação, extrair o bloco, o pedaço ou a placa do material recém-dormido e como um bicho que foi retirado a pele, expô-lo ao mundo, mostrar à carne viva a dor de estar nele, até que estimule a se redimir, voltando a sua forma ancestral.

Estocagem \#6 dispõe para sinalizações de um projeto de apresentação que falha em sua concepção. O que se apresenta é justamente esse âmbito do não concluso, objetivado ou alcançado. E é justamente neste estado de inacabamento ou fracasso em que vai se percorrendo experiências com a matéria que não estão circunscritas à objetividade, que trazem resultados findos, que percorrem com linearidade, mas que operam na subjetividade, nos últimos caminhos possíveis que a experiência tátil propõe. Sonhar a matéria é estocar desejos, experiências, contato e levá-los consigo na mente ou na mão.

\section{SINALIZAÇÕES DE SOTERRAMENTOS}

Estocagem \#6 mesmo se orientando rumo à parede, no qual a ela está pregada, se compromete a expor através da existência de um corte frontal de uma caixa de madeira 
fechada, blocos estocados de glicerina. Esses blocos por sua vez, se projetam para fora ou melhor, para a frente do espectador, exibindo toda sua toponímia horizontal. Ao serem manuseados, tocados ou manipulados, toda a sorte de apreensões é acionada. Atenho-me pois, à apreensão de uma prevalência da forma de apresentação desses blocos de glicerina que se oriente para uma horizontalidade estocada, armazenada, como também, de toda uma massa que ocupa os espaços da obra, as mãos dos espectadores, a experiência com a obra. Esses corpos em movimentos apresentam memória de superfície que trazem consigo não só das interações obra-manuseador, mas de sua protoestocagem, como marcas de camada sobre camada, sedimentação da matéria, marcas de secagem.

Esta forma de apresentação que mesmo vertical se remete à questões horizontais em seu interior, à processos da matéria como o verter líquido sobre um molde, recebe em sua horizontalidade continente este que se espraia para solidificar e que após recebe sobre suas costas outros líquidos que também se espraiam, se aderem, se horizontalizam, sinalizando para o conceito operatório conhecido na pesquisa, apropriado e dilatado dos processos geológicos em que

emprego o termo soterramento (processo que se relaciona com os conceitos acima) para me referir a essa ação de cobertura de objetos com matéria-doce. Amplio o conceito de soterramento ao nomear uma ação que não necessariamente ocorre pela sobreposição de terra sobre um objeto, mas pela sobreposição de matéria-doce. $\mathrm{O}$ uso do termo soterramento melhor se encaixa como termo para nortear a ação de cobrir objetos que se relacionam com a natureza, devido ao seu caráter mais provisório, recém-ocorrido, prematuro. (BATISTA 2016, p.18)

O espectador ao se envolver com os blocos de glicerina, melhor dizendo, matériadoce, presencia momentos de estocagens de um corpo disposto em seu local de descanso. Há uma aproximação referencial desses objetos aos corpos mortos que jazem horizontalmente em seus túmulos. Há a sinalização de uma relação de cúmplices que “testemunha não meramente 'o significado interno' da horizontalidade do trabalho mas também à baixeza desta condição". ${ }^{3}$ (BOIS e KRAUSS, 1997, p. 95, tradução nossa). Essa horizontalidade se refere pois a uma horizontalidade de morte, de corpo rúptil que se decompõe, que se desfaz. Estocagem \#6 é justamente uma obra que expõe a céu aberto

\footnotetext{
${ }^{3}$ Citação original: “(...) testifies not merely to 'the internal meaning' of the work's horizontality but also to the 'bassesse' of this condition."
} 
a comparação a um corpo em descanso, que se decompõe pelo tempo não metrificado, mas pelos tempos instaurados pelas experiências de inúmeros vilipendiadores, manuseadores, manipuladores ou espectadores que colaboram conscientes ou não com sua destruição, roubo ou transporte quer queiram, quer não.

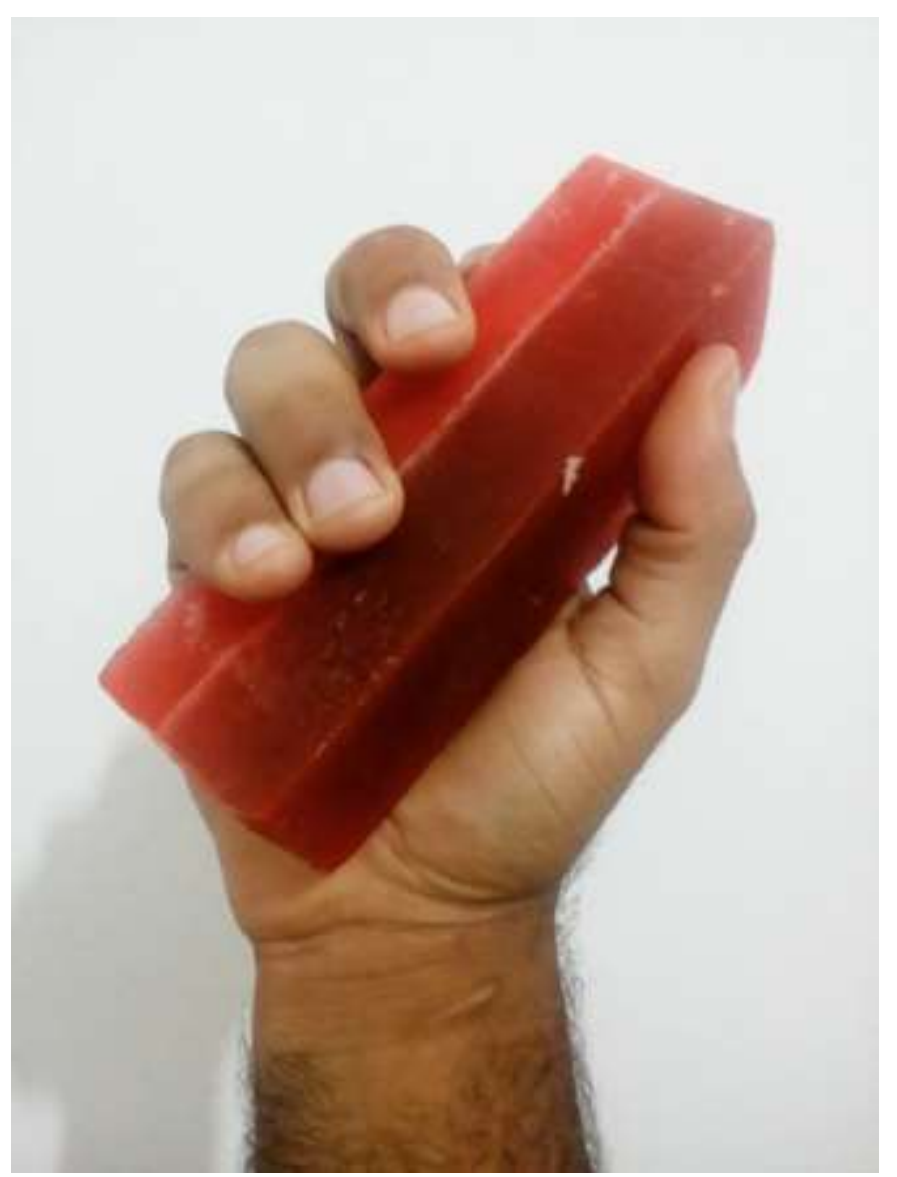

Figura 3: Fercho Marquéz. Estocagem \#6 (Detalhe do bloco de glicerina). Fonte: acervo pessoal.

A glicerina mantém seu percurso de horizontalidade desde sua solidificação em molde disposto sobre o chão, seu estoque num recipiente horizontal e que é fustigada sua genealogia em um caos sem direção ou posição únicas na multidirecionalidade que o contato da derme humana promove ao capturá-la (fig. 3). Como intempérie o contato humano vai desbastando, corroendo com seus óleos, carcomendo ou alisando: a pretensa geometria desenforma, torna orgânico em uma aproximação por semelhança ao orgânico das mãos, dos óleos, das influências climático-ambientais. A estocagem falha em sua responsabilidade de fazer a glicerina permanecer, já que a força desagregadora que ativa a obra, através do público, do meio e do tempo compromete suas funções precisas, constantes e permanentes, permitindo desagregações. 
O contato dos manuseadores com os blocos de glicerina que se desintegram pouco a pouco contribuem para que o material se encontre em constante estado de instabilidade de sua existência. Processos entrópicos são acionados pelo calor e pela oleosidade que a mão e a pele, respectivamente possuem, como também, por outros usos temporários na experiência que cada manuseador terá com este corpo rúptil. A obra então é fadada desde sua conceptualização a morrer, a desagregar-se. O percurso fúnebre, ou seja todo o processo, está presente no processo artístico, como também é a sua personificação. Todo processo de dissolução de um corpo, de degradação é explicada pela segunda lei da termodinâmica, ou seja pela entropia:

O exemplo de entropia de Roger Caillois é simples: água quente e gelada se misturando juntas para se acomodarem em uma brandura uniformemente morna. $\mathrm{O}$ de Robert Smithson é só um pouco mais complexo. Para explicar a entropia, ele pede para seu leitor imaginar um tanque de areia cheia de um lado com areia branca e do outro com negra. Um garotinho começa a correr ao redor do cerco em sentido horário, movimentando a areia à medida que ele corre e mistura os grãos escuros juntamente com os claros. É dito a ele então para reverter seu curso e correr em sentido anti-horário. Isto certamente nada fará para desfazer o movimento em direção a uniformidade e reordenar as duas cores em espaços diferentes. À medida que suas pernas continuam a se moverem, o processo de entropia, irreversivelmente, apenas progredirá e se intensificará. ${ }^{4}$ (BOIS; KRAUSS, 1999, p.73, tradução minha)

E como um caminho sem volta, a glicerina se adere à pele do manuseador que será carregada para qualquer lugar, mais uma coisa caberia explicitar: o simples fato da glicerina deixar para sempre sua estocagem, de não poder voltar para o mesmo lugar é que potencializa mais sua característica de projétil, de flecha lançada que sobe no ar e que desce, seguida pela gravidade rumo à mão de alguém. Seus corpos vermelhos, convidativos e tentadores, que estão dispostos dos mais claros aos mais escuros e de cima para baixo em seus nichos são removidos e repostos, glicerina se prende na entrada do

\footnotetext{
${ }^{4}$ Citação original: "Roger Caillois's example of entropy is simple: hot and cold water mixing together to settle into a uniformly tepid blandness. Robert Smithson's is only somewhat more complex. To explain entropy he asks his reader to imagine a sandbox filled on one side with white sand and on the other with black. A little boy begins to run around the enclosure in a clockwise direction, kicking up the sand as he goes and mixing together dark grains with light. He is then told to reverse his course and run counterclockwise. This will certainly do nothing to undo the movement toward uniformity and re-sort the two color sinto separate fields. As his legs continue to churn, the process of entropy will, irreversibly, only progress and deepen."
} 
nicho dada à fricção pela parte frontal da caixa, o calor promove seu suor liberando óleo que lambuza e também seguindo a gravidade, escorre.

Trata-se de uma abordagem do comportamento dos materiais que não passa pelos princípios da mecânica dos sólidos e da geometria. [...] Tudo se passa no chão, onde os materiais se acumulam, se amontoam, escorregam e se dispersam. Os materiais são governados pelo peso. Tudo cai, tudo se acumula no chão. Uma operatória das precipitações se estabelece aqui. Movimentos descendentes, derrubamentos, desagregação estrutural, constituição de estratos. Verticalidade dá lugar à horizontalidade. ${ }^{1}$ (PEIXOTO, 2013, p.15)

Estocagem \#6 mesmo disposta através da frontalidade, porta em si, na ideia de obra, mas também literalmente dentro, objetos horizontais que se projetam fisicamente para fora, num primeiro momento e metaforicamente para baixo em um segundo, convocando os manuseadores para uma aproximação com a obra. Se o que a obra evoca, segundo BOIS e KRAUSS (1997, p.95) for "se não intenções em busca do baixo," no entanto pois, "é a nova relação do espectador com o quadro", neste caso, o objeto, "como se ele fosse um campo no qual ele ou ela estariam olhando para baixo", neste caso para a própria mão, ou para o chão onde se encontra o molde da glicerina que a recebe, o chão em que pisamos.

\section{SINALIZAÇÕES DO QUE ESTÃO POR VIR - CONSIDERAÇÕES}

Nos três primeiros capítulos, discorro sobre os conceitos operatórios que estão presentes no processo artístico e que se apresentam por sinalizações sutis na obra Estocagem \#6: os processos silenciosos, as estocagens e os soterramentos. Levanto questionamentos sobre como o espectador contribui com o acionamento de processos na obra; os processos matéricos que se locomovem no espaço-obra, espaço-corpo do espectador; uma estocagem que se apresenta como falha; o processo anterior ao de apresentação da obra, especialmente dentro do processo de manipulação da glicerina, a dizer da protoestocagem; a obra que dialoga com as questões de ruptilidades como a entropia e a horizontalidade.

${ }^{5}$ (...) If not the intentions to lowness, is the viewer's new relation to the canvas as though it were a field onto which he or she were looking down. 
Estocagem \#6 se apresenta frontalmente como um desafio a quem está a sua frente. Mesmo se acionando por contato do espectador, é de dentro do corpo da obra que literalmente escapa o vetor de ação: como se fosse uma sinalização de precaução, em que o animal mesmo assim, sabendo do perigo de captura, é preso pela armadilha já acionada. Há uma emboscada para aquele que quer tocar, manusear. Estocagem \#6 apresenta sinalizações conceituais, anteriormente descritas, mas que também se constitui como sinalizadora em si mesma.

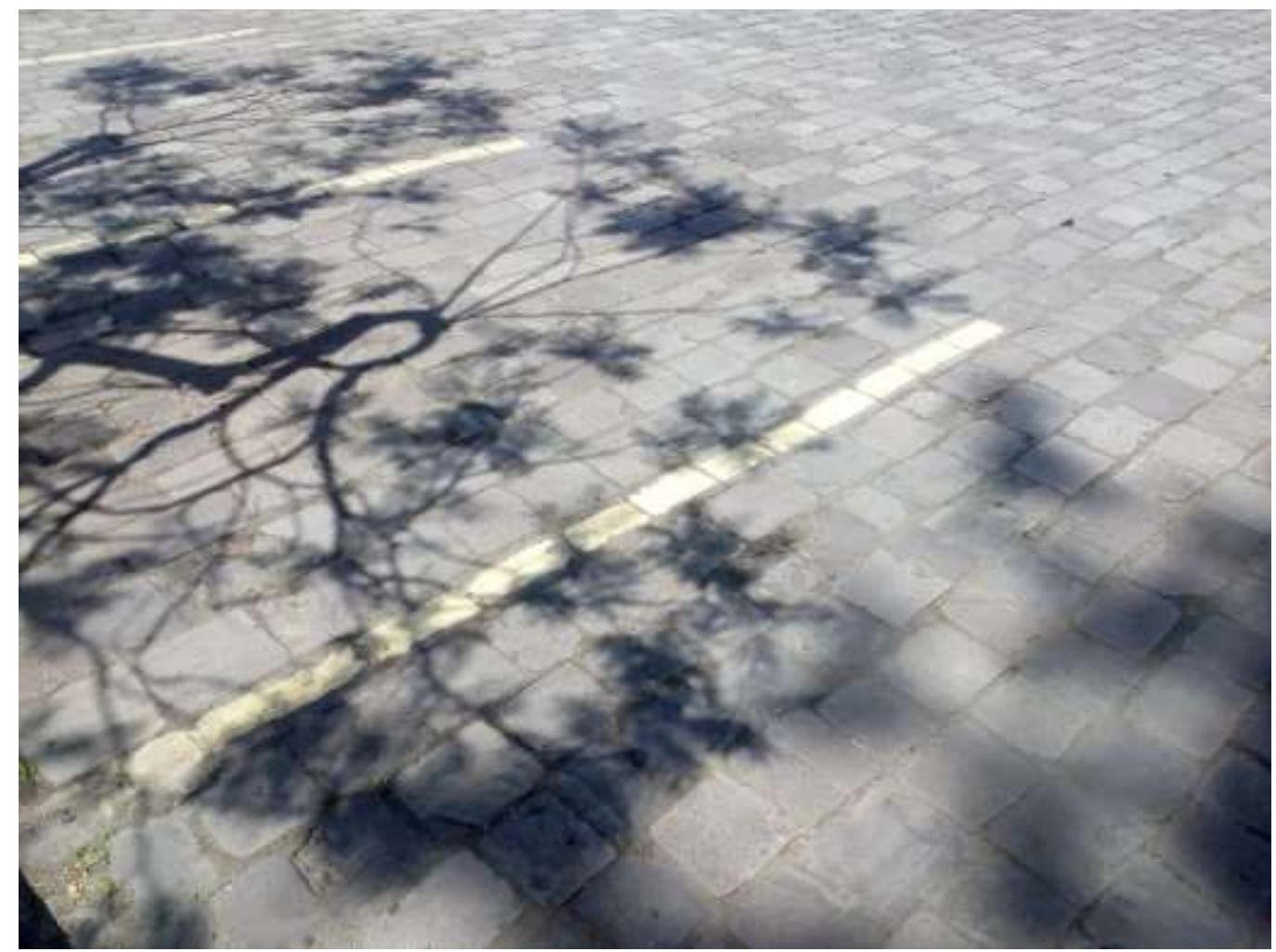

Figura 5: Fercho Marquéz. Sem título. Fotografia. 2017. Fonte: acervo do artista. 


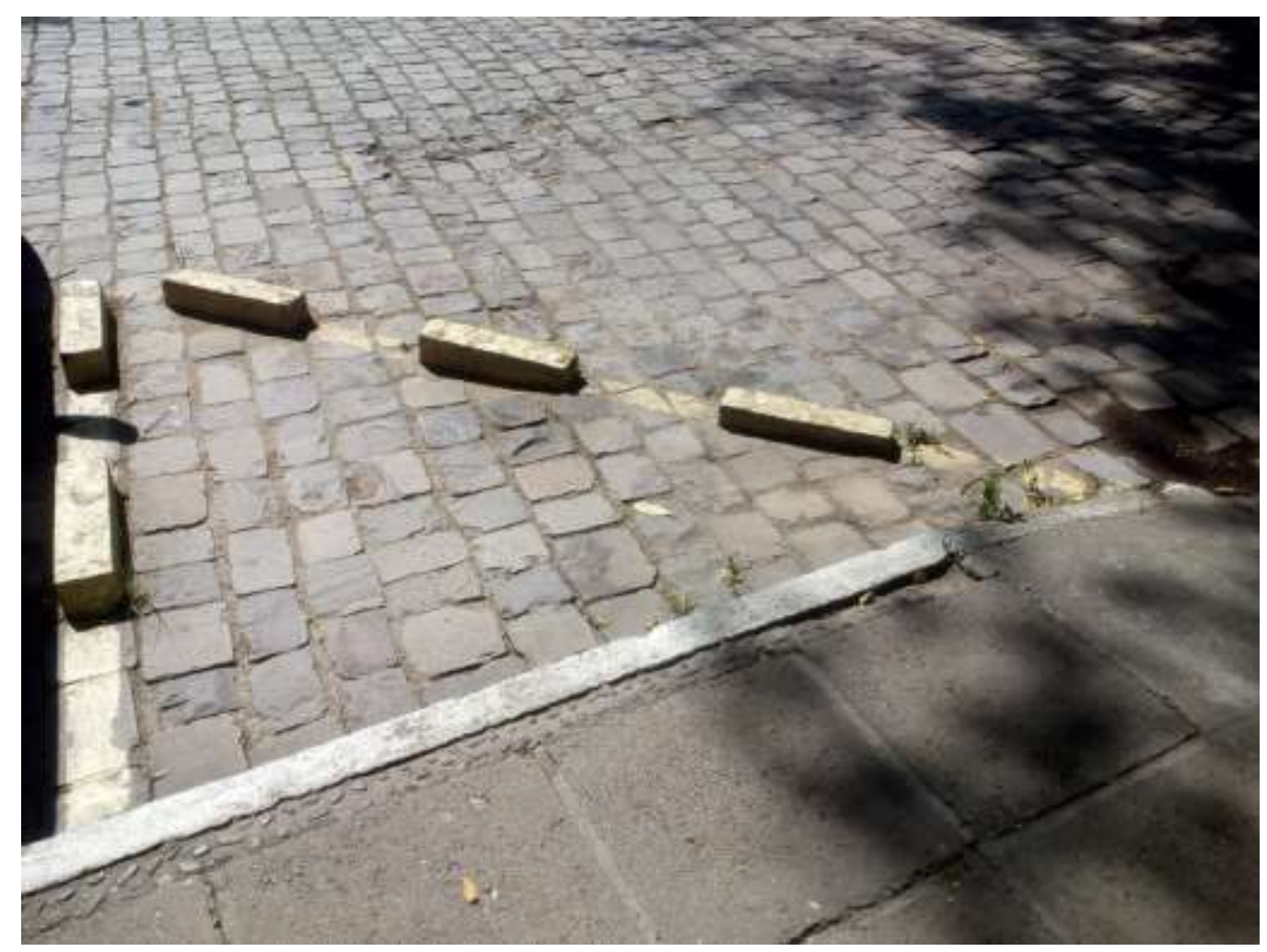

Figura 6: Fercho Marquéz. Sem título. Fotografia. 2017. Fonte: Acervo do artista

Um objeto frontal que escapa matéria para fora e que porta em si, toda a horizontalidade de seu percurso, de sua estocagem, de sua manipulação. Este objeto remete às sinalizações presentes no mundo. Bandeiras marítimas, placas de trânsito, faixas e obstáculos de rua: são sinalizações que comunicam na maioria das vezes algo que se relaciona a nossa posição de contato com o mundo: o solo, o chão, a rua, o piso. Similar a isto, a obra dialoga com a exposição de um processo de estocagem não concluso, consequentemente objetos guardados dentro convidam à manipulação e à sua não permanência. A obra aponta e se projeta para o espectador, o espectador se transforma em manuseador ao aceitar para si como convite o experimento.

Esse jogo de atração é percebido como um campo que se desprega da parede, rompe espaços que distanciam espectadores e obra e mutualmente se tocam, se transformam, se atualizam. Na obra de Jasper Johns, Target with Four Faces é possível perceber o alvo como sinalizador de uma atração, a movimentação da atração advinda da obra e que vai em direção ao espectador e que é rebatido pela pungência através do olho humano, ou seja, do espectador rumo a obra como um dardo. Se em Estocagem \#6, há a sobreposição de maior potência da obra que se desprega do conjunto e se impregna ao corpo que tocou, em Target with Four Faces há a sobreposição do olho do espectador que 
penetra o campo visual da tela, contrastando com os quatros rostos que não podem ver presentes na obra.

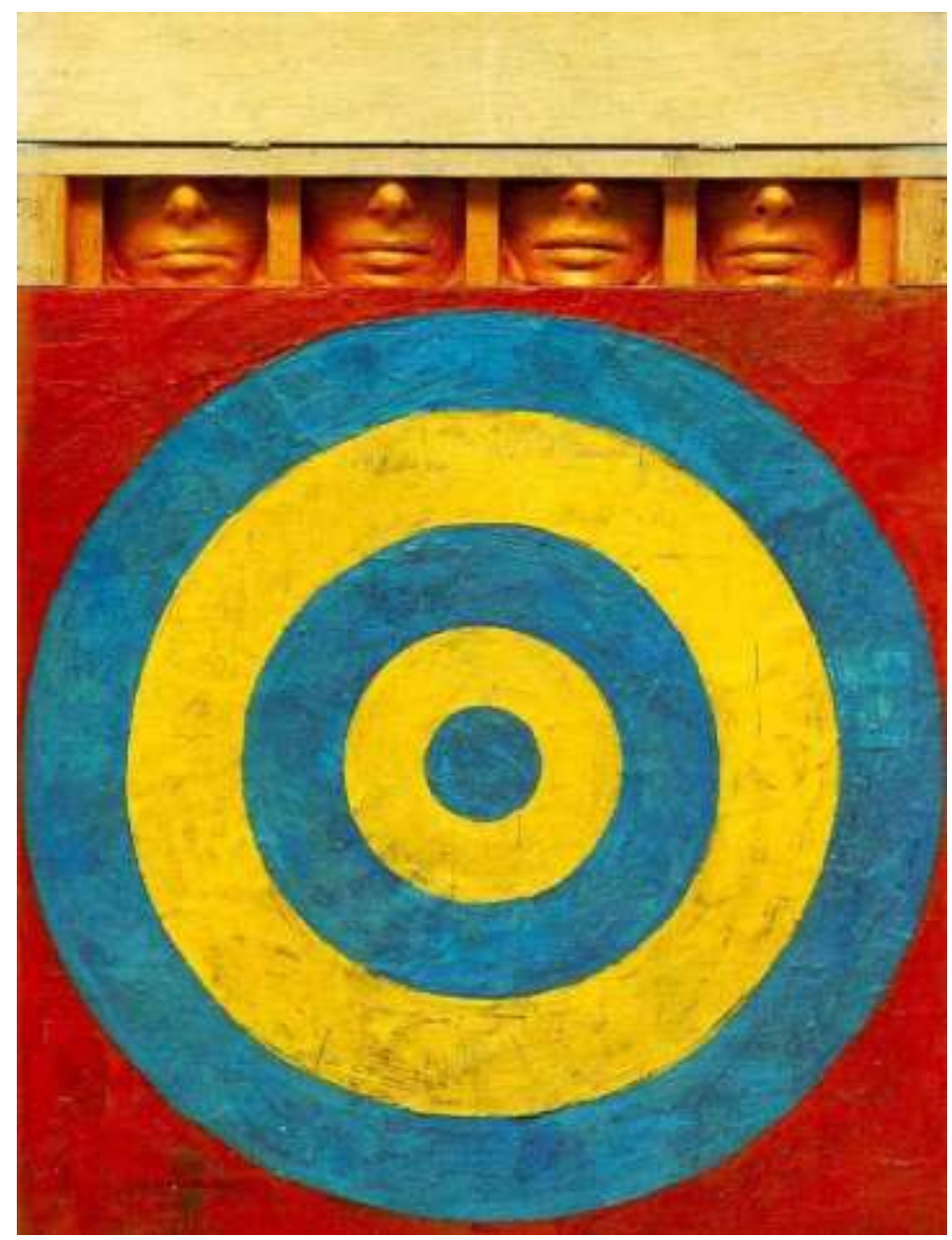

Figura 6 : Jasper Johns. Target with Four Faces. Encaustica sobre jornal e tela, madeira e gesso, 85.3 x 66 x $7.6 \mathrm{~cm}$. Fonte: Acervo do MoMA.

A obra Estocagem \#6 vem sinalizar e ao mesmo tempo é sinalizadora em si. Totêmica ou esfíngica, deixa armada seus encantos através da vontade do espectador de tocá-la, mas que finca sorrateiramente com malemolência sua marca: essa marca não está no conjunto dos blocos de glicerina estocados na caixa. A marca está no próprio corpo das pessoas, especialmente aquelas partes em que foram dadas a oportunidade de interação com a obra. A obra então impregna nessa superfície, na experiência estacionadora e se rompe, se quebra. Vai sendo absorvida, decantando, a mente, pois, se impregna no sonho do embrenhar, encanta-se, e se quebra:

a mente e a terra encontram-se em um processo constante de erosão: rios mentais desgastando rochedos de pensamento, ideias se decompõem em pedras de desconhecimento, e cristalizações 
conceituais desmoronam em resíduos arenosos de razão. (SMITHSON, 2009, p. 182)

É a metáfora de placa de transito que não ordena ações e sim aponta para o rumarse em direção ao território do rúptil, território esse que se encontra no mundo, das coisas, pessoas situações e tempos em suas existências aparentemente estáveis e constantes mas que escondem todo um arcabouço de um mundo em eterna ruptura. Esse placar não é o da contemplação para depreender qual rota tomar, mas justamente o tocar com olhos cegos à visualidade esse mundo e percorrer com o tato o mundo topográfico da experiência perante aquilo que se adere ao nosso corpo: a morte que já vem aderida à nossa existência, que nos torna necessários em vida para sua completude na morte.

Estocagem \#6 não é apenas um dispositivo que me aponta novas relações e caminhos processuais e poéticos no andamento da pesquisa, mas sim a própria sinalização: é o poste que indica onde está o cemitério clandestino, é o aviso de fim da margem do atoleiro e o seu início indistinguivelmente traiçoeiro, é o. Apresentada em sua verticalidade externa e horizontalidade interna, a obra tem para si, neste momento, em sua existência, a importância ontológica. Tem também sua importância originária, nascente de proposição de estados rúpteis: ela apenas reporta algo a alguém. Ela apenas é um dispositivo que intermedia o sujeito rúptil com o mundo rúptil, da experiência de rompimento, através da glicerina com corpo humano em sua própria instabilidade corporal.

Como um memento mori, está mais próxima da ideia de tumba do que da rápida relação com sua verticalidade. É a sinalização própria do mundo afora, das pessoas que vivem nele, da morte escamoteada nele: Estocagem \#6 indica o externo de si mesma, o espaço da galeria e principalmente, o mundo. É para o fora que vamos quando morremos, é para a lápide, para o caixão, para a terra. Tornamo-nos tumba, tornamo-nos aviso de morte, mise en tombe $e^{6}$ para os vivos. Esta obra é poetizada em sua traiçoeira frontalidade: está tão próxima que toca o nariz, não necessariamente os olhos. Quando os olhos percebem, já foram fisgados, já estão presos na armadilha, já se encontram capturados ao próprio molde que se destina à morte, à ruptilidade. Como terra líquida, a glicerina vai

\footnotetext{
${ }^{6}$ Para mais informações sobre o termo mise en tombe está disponível no artigo ainda não publicado intitulado Considerações sobre o interior da escultura-tumba: escoamentos através do invisível na obra Estocagem \#8, escrito em 2017.
} 
adentrando sem perceber, vai sufocando, vai matando. Material rúptil encontra material rúptil que não sabe que é rúptil. Material rúptil mata material rúptil. Esta é a sinalização. 


\section{REFERÊNCIAS}

BATISTA, Anderson dos Santos. Ruptilidade da vida, ductilidade da morte. 2015. 68 páginas. Trabalho de Conclusão de Curso (Graduação em Artes Visuais) - Universidade Estadual de Londrina, Londrina, 2015.

BOIS, Yve-Alain e KRAUSS, Rosalind. Formless: a user's guide. New York: Zone Books, 1999.

SMITHSON, Robert. Uma sedimentação da mente: projetos de terra. IN: COTRIM, Cecilia e FERREIRA, Glória [orgs]. Escritos de artistas: anos 60/70. Rio de Janeiro: Jorge Zahar, 2009.

PEIXOTO, Nelson Brissac. Paisagens críticas: Robert Smithson: arte, ciência e indústria. São Paulo: EDUC, Senai, FASESP, 2010. 